\title{
Peculiarities of valence band formation in As-Ge-Se semiconductor glasses
}

\author{
M. Vakiv ${ }^{1}$, R. Golovchak ${ }^{1}$, D. Chalyy ${ }^{2}$, M. Shpotyuk ${ }^{1,3}$, S. Ubizskii ${ }^{3}$, O. Shpotyuk ${ }^{1}$ \\ ${ }^{I}$ Scientific Research Company ,, Carat”, 212, Stryiska str., 79031 Lviv, Ukraine \\ ${ }^{2}$ Lviv State University of Vital Activity Safety, 35, Kleparivska str., 79000 Lviv, Ukraine \\ ${ }^{3}$ Lviv Polytechnic National University, 12, Bandery str., 79013 Lviv, Ukraine
}

\begin{abstract}
Peculiarities of valence bands formation in As - Ge - Se semiconductor glasses have been investigated within $\mathrm{As}_{x} \mathrm{Ge}_{x} \mathrm{Se}_{1-2 x}$ cut of glass forming region by highresolution X-ray photoelectron spectroscopy (XPS). It is shown that compositional dependence of XPS valence band spectra of the investigated glasses correlates well with previously obtained data for constituent glasses of binary $\mathrm{Ge}_{x} \mathrm{Se}_{1-x}$ and $\mathrm{As}_{x} \mathrm{Se}_{1-x}$ systems. In particular, increase in $x$ leads to the decrease in the intensity of bands at $\sim 2 \mathrm{eV}$ responsible for Se $l p$-states. The valley at $\sim 3 \mathrm{eV}$ is filled by electronic states originated from $\mathrm{Se}-\mathrm{Ge}$ and $\mathrm{Se}$ - As bonds. An accompanying decrease in the intensity of the band at $\sim 5 \mathrm{eV}$ is explained by a decrease in Se $4 p$ bonding states associated with Se - Se covalent bonds.
\end{abstract}

Keywords: chalcogenide vitreous semiconductors, high-resolution X-ray photoelectron spectroscopy, valence band.

Manuscript received 30.12.11; revised version received 18.01.12; accepted for publication 26.01.12; published online 29.02.12.

\section{Introduction}

Network glasses based on chalcogens (i.e. chalcogenide vitreous semiconductors - ChVS) are unique disordered solids widely used in IR optoelectronics and photonics as high efficiency optical amplifiers in optical communication networks, memory or switching devices, high-resolution inorganic photoresists, media for submicrometer lithography process, antireflection coatings, etc. [1-4]. Ones of the most commercially efficient ChVS are the glasses of ternary As-Ge-Se system. In particular, high optical transparency in the IR spectral region made possible use of these ChVS by Amorphous Materials Inc. and UMICORE IR Glasses for commercial production of IR optical elements, notably AMTIR $\left(\mathrm{As}_{0.12} \mathrm{Ge}_{0.33} \mathrm{Se}_{0.55}\right)$ [5] and GASIR $\left(\mathrm{As}_{0.20} \mathrm{Ge}_{0.22} \mathrm{Se}_{0.58}\right)[6,7]$, respectively. That is a reason for many papers published in recent years and devoted to investigation of various physical properties of these ChVS, including Raman spectroscopy [8], elastic moduli measurements [9], thermal characterization [10], vibrational density-of-states calculations [11], extended $\mathrm{X}$-ray absorption fine-structure spectroscopy studies [12], X-ray photoelectron spectroscopy [13], etc. Despite high attention to these materials, electronic structure of As - Ge - Se ChVS is not studied enough, which limits their practical implementation. However, understanding of the main regularities in formation of ChVS electronic structure can help to develop new optoelectronic functional devices, capable to explore atomic and electronic subsystems of ChVS with the same efficiency. Just recently, it was demonstrated with the example of valence band compositional dependences in binary ChVS [14]. Any reports on the analogous investigations in ternary As - Ge - Se ChVS are absent, even if these materials are more commercially efficient.

Therefore, in this work we have performed complex and systematic investigations of the peculiarities of valence band formation in ternary As - Ge - Se ChVS within the $\mathrm{As}_{x} \mathrm{Ge}_{x} \mathrm{Se}_{1-2 x}$ cut of glassforming region by high-resolution X-ray photoelectron spectroscopy (XPS). 


\section{Experiment}

The ChVS samples of $\mathrm{As}_{x} \mathrm{Ge}_{x} \mathrm{Se}_{1-2 x}$ cut $(x=0.05,0.07$, $0.09,0.11,0.14,0.16,0.18,0.20,0.25$ and 0.30 ) were chosen for this investigation. Samples were prepared by conventional melt-quench method from a mixture of the high-purity elemental germanium, elemental selenium and $\mathrm{As}_{2} \mathrm{Se}_{3}$ glass in evacuated $\left(\sim 10^{-6}\right.$ Torr $)$ silica ampoules. The sealed ampoules containing $\sim 10 \mathrm{~g}$ of the raw ingredients were gradually heated $\left(2^{\circ} \mathrm{C} / \mathrm{min}\right)$ up to $950^{\circ} \mathrm{C}$ in a rocking furnace. They were rocked during $48 \mathrm{~h}$ at the highest temperature in order to make the melt homogenous. The melt was quenched by switching off the furnace that cooled down to ambient temperature for about 14 hours.

High resolution XPS spectra were recorded with a Scienta ESCA-300 spectrometer using monochromatic $\mathrm{Al} K_{\alpha} \mathrm{X}$-rays $(1486.6 \mathrm{eV})$ under vacuum $\left(2 \times 10^{-8}\right.$ Torr. As far as XPS is the method to study surface, the samples were fractured directly in the spectrometer chamber under high vacuum for investigation of the bulk properties of the ChVS (fresh fractures were investigated). The analyzed area was a spot $\sim 3-4 \mathrm{~mm}$ long and $\sim 250 \mu \mathrm{m}$ wide. In all the measurements, the angle between the surface and detector was $90^{\circ}$. The energy scale was calibrated using the Fermi level of pure Ag. The surface charging from photoelectron emission was neutralized using a low energy $(<10 \mathrm{eV})$ electron flood gun. The reproducibility of the measurements was checked on different regions of fractured surfaces as well as on different samples. The XPS data consisted of survey scans over the entire binding energy (BE) range and selected scans over the valence band. An energy increment of $1.0 \mathrm{eV}$ was used to record the survey spectra and $0.1 \mathrm{eV}$ for the valence band ones. The valence band spectra were recorded using the constant pass energy of $300 \mathrm{eV}$. The experimental positions of the valence band and core levels for all the investigated samples were adjusted by referencing to the $4 f_{7 / 2}$ core level peak of pure $\mathrm{Au}$ at $84.0 \mathrm{eV}$ as described elsewhere [15].

Data analysis was performed with the standard CASA-XPS software package. Intensities of the XPS signals recorded for different samples were normalized to the high-energy background level for comparison.

\section{Results and discussion}

XPS survey spectra of the investigated $\mathrm{As}_{x} \mathrm{Ge}_{x} \mathrm{Se}_{1-2 x}$ ChVS are shown in Fig. 1. Identification of the corresponding bands was performed using the reference spectra in the PHI handbook for monochromatic $\mathrm{Al}_{\alpha} \mathrm{X}$ rays $(1486.6 \mathrm{eV})$ [16]. As it is obvious from Fig. 1, only peaks corresponding to the electronic states of $\mathrm{As}, \mathrm{Ge}$ and $\mathrm{Se}$, as well as related Auger electrons are observed in the experimental XPS survey spectra. It is evidence for the absence of significant concentration of impurities (mainly oxide complexes), which could complicate interpretation of the observed XPS valence band spectra.

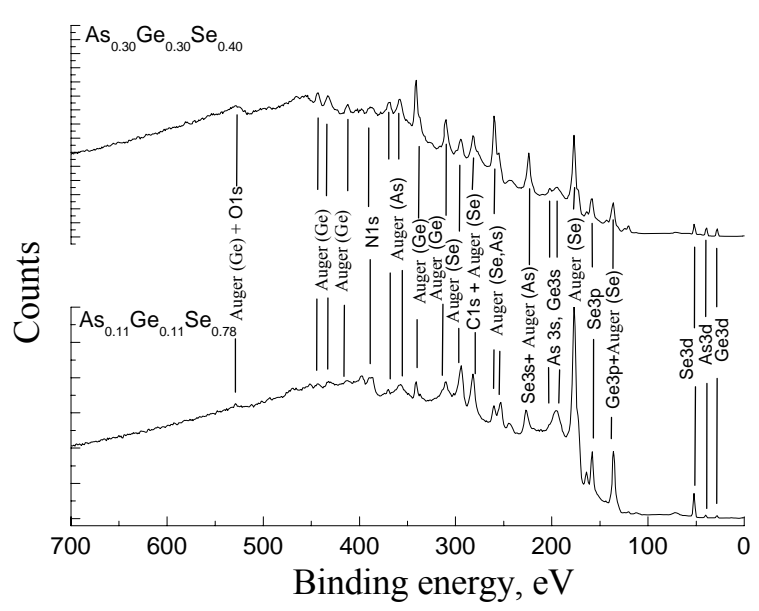

Fig. 1. XPS survey spectra of the typical $\mathrm{As}_{x} \mathrm{Ge}_{x} \mathrm{Se}_{1-2 x} \mathrm{ChVS}$.

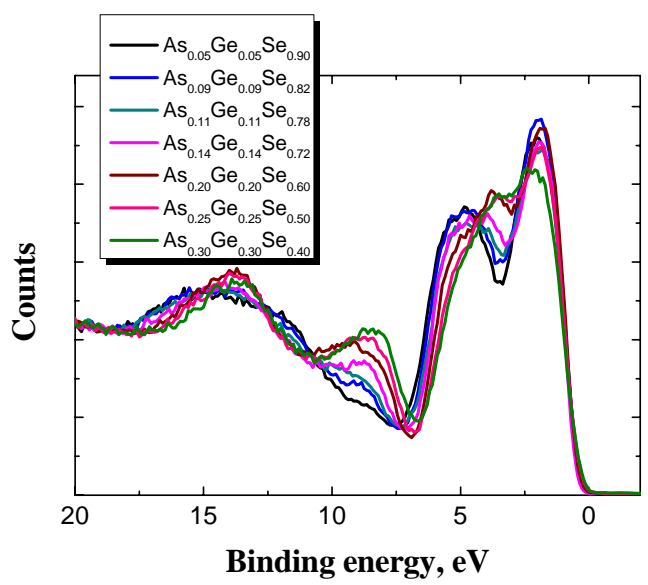

Fig. 2. XPS spectra of the $\mathrm{As}_{x} \mathrm{Ge}_{x} \mathrm{Se}_{1-2 x}$ ChVS valence bands.

Compositional dependence of XPS valence band spectra for ternary $\mathrm{As}_{x} \mathrm{Ge}_{x} \mathrm{Se}_{1-2 x} \mathrm{ChVS}$ is shown in Fig. 2. Main features of the valence bands are in good agreement with previously obtained data for constituent binary $\mathrm{Ge}_{x} \mathrm{Se}_{1-x}$ and $\mathrm{As}_{x} \mathrm{Se}_{1-x}$ ChVS [14]. The welldefined contributions from lone pair $(l p)$ electrons $(\sim 2 \mathrm{eV}), 4 p$ bonding states $(\sim 5 \mathrm{eV})$ and $4 s$ electrons $(\sim 11-16 \mathrm{eV})$ of $\mathrm{Se}$ atoms are prominently visible in Fig. 2 for chalcogen-rich ChVS samples. Increase in $\mathrm{Ge}$ and As concentrations within the $\mathrm{As}_{x} \mathrm{Ge}_{x} \mathrm{Se}_{1-2 x}$ system leads to the same modification in valence band spectra as in the case of binary $\mathrm{Ge}_{x} \mathrm{Se}_{1-x}$ and $\mathrm{As}_{x} \mathrm{Se}_{1-x}$ systems [14]. Particularly, increase of $x$ leads to the drop in the intensity of XPS signal from $\mathrm{Se} l p$ electrons at $\sim 2 \mathrm{eV}$. At the same time, the valley at $\sim 3 \mathrm{eV}$ begins to fill by electronic states due to the increased number of $\mathrm{Se}-\mathrm{Ge}$ or $\mathrm{Se}-\mathrm{As}$ bonds. It accompanies by the decrease in the band intensity at $\sim 5 \mathrm{eV}$ explained by a decrease in the density of Se $4 p$ bonding states associated with $\mathrm{Se}-\mathrm{Se}$ covalent bonds [14]. Consequently, the other two bands 
in $\mathrm{As}_{x} \mathrm{Ge}_{x} \mathrm{Se}_{1-2 x}$ XPS valence band spectra at $\sim 8 \mathrm{eV}$ and at $\sim 14 \mathrm{eV}$ are associated with overlapped Ge and As $4 s$ states. In contrast to sulfur-based $\mathrm{Ge}_{x} \mathrm{Se}_{1-x}$ and $\mathrm{As}_{x} \mathrm{Se}_{1-x}$ ChVS systems, significant sharpening the overall band $(0-7 \mathrm{eV})$ was observed with decrease of Se concentration in $\mathrm{Ge}_{x} \mathrm{Se}_{1-x}$ and $\mathrm{As}_{x} \mathrm{Se}_{1-x}$ ChVS systems [14]. The same effect is also inherent to the investigated ternary $\mathrm{As}_{x} \mathrm{Ge}_{x} \mathrm{Se}_{1-2 x}$ ChVS system (Fig. 2).

As it is obvious from these investigations on the compositional dependences of valence bands for ternary $\mathrm{As}_{x} \mathrm{Ge}_{x} \mathrm{Se}_{1-2 x}$ ChVS, the density-of-states in the valence band depends on the chemical composition, particularly, on the content of the most electro-negative element (Se in our case). The wide glass forming region of this ChVS system allows smooth changing the density-of-states in the valence band, which can play a significant role in the development of novel ChVS-based optoelectronic devices.

\section{Conclusions}

Systematic variation of composition in $\mathrm{As}_{x} \mathrm{Ge}_{x} \mathrm{Se}_{1-2 x}$ ChVS system allows accomplishing a more precise analysis and identification of XPS spectral features than those obtained from the data of only one composition. It is shown that observed features in the valence band electronic structure are determined by chalcogen content in the investigated glasses.

\section{References}

1. J.S. Sanghera and I.D. Aggarwal, Active and passive chalcogenide glass optical fibers for IR applications: a review // J. Non-Cryst. Solids, 256257, p. 6-16 (1999).

2. B. Bureau, X.H. Zhang, F. Smektala, J.-L. Adam, J. Troles, H. Ma, C. Boussard-Pledel, J. Lucas, P. Lucas, D. Le Coq, M.R. Riley and J.H. Simmons, Recent advances in chalcogenide glasses // J. Non-Cryst. Solids, 5\&346, p. 276-283 (2004).

3. A. Kovalskiy, M. Vlcek, J. Cech, W.R. Heffner, C.M. Waits, M. Dubey and H. Jain, Chalcogenide glass e-beam and photo-resists for ultrathin gray scale patterning // J. Micro/Nanolithography,8(4), p. 043012-1-043012-11 (2009).

4. S.K. Sundaram, B.R. Johnson, M.J. Schweiger, J.E. Martinez, B.J. Riley, L.V. Saraf, N.C. Anheier, Jr., P.J. Allen and J.F. Schultz, Chalcogenide glasses and structures for quantum sensing // Proc. SPIE,5359, p. 234-245 (2004).
5. D.-Y. Choi, S. Madden, A. Rode, R. Wang and B. Luther-Davies, Fabrication of low loss $\mathrm{Ge}_{33} \mathrm{As}_{12} \mathrm{Se}_{55}$ (AMTIR-1) planar waveguides // Appl. Phys. Lett. 91, p. 011115-1-011115-3 (2007).

6. Y. Guimond, J. Franks and Y. Bellec, Comparison of performances between GASIR moulded optics and existing IR optics // Proc. SPIE, 5406, p. 114120 (2004).

7. Y. Guimond and Y. Bellec, Molded GASIR ${ }^{\circledR}$ infrared optics for automotive applications // Proc. SPIE, 6206, p. 62062L-1-62062L-6 (2006).

8. R.P. Wang, A. Smith, A. Prasad, D.Y. Choi and B. Luther-Davies, Raman spectra of $\mathrm{Ge}_{\mathrm{x}} \mathrm{As}_{\mathrm{y}} \mathrm{Se}_{1-\mathrm{x}-\mathrm{y}}$ glasses // J. Appl. Phys. 106, p. 043520-1-043520-4 (2009).

9. R.P. Wang, A. Smith, B. Luther-Davies, H. Kokkonen and I. Jackson, Observation of two elastic thresholds in $\mathrm{Ge}_{\mathrm{x}} \mathrm{As}_{\mathrm{y}} \mathrm{Se}_{1-\mathrm{x}-\mathrm{y}}$ glasses // $\mathrm{J}$. Appl. Phys. 105, p. 056109-1-056109-3 (2009).

10. R.P. Wang, C.J. Zha, A.V. Rode, S.J. Madden and B. Luther-Davies, Thermal characterization of $\mathrm{Ge}-\mathrm{As}-\mathrm{Se}$ glasses by differential scanning calorimetry // J. Mater. Sci.: Mater. Electron. 18, p. S419-S422 (2007).

11. W.A. Kamitakahara, R.L. Cappelletti, P. Boolchand, B. Halfpap, F. Gompf, D.A. Neumann and H. Mutka, Vibrational densities of states and network rigidity in chalcogenide glasses // Phys. Rev. B, 44(1), p. 94-100 (1991).

12. S. Sen and B.G. Aitken, Atomic structure and chemical order in Ge-As selenide and sulfoselenide glasses: An X-ray absorption fine structure spectroscopic study // Phys. Rev. B, 66, p. 134204-1-134204-10 (2002).

13. R.P. Wang, A.V. Rode, D.Y. Choi and B. LutherDavies, Investigation of the structure of $\mathrm{Ge}_{x} \mathrm{As}_{y} \mathrm{Se}_{1-x-y}$ glasses by X-ray photoelectron spectroscopy // J. Appl. Phys. 103, p. 083537-1083537-5 (2008).

14. S. Kozyukhin, R. Golovchak, A. Kovalskiy, O. Shpotyuk and H. Jain, Valence band structure of binary chalcogenide vitreous semiconductors by high-resolution XPS // Fizika Tekhnika Poluprovodnikov, 45(4), p. 433-436 (2011), in Russian.

15. R. Golovchak, A. Kovalskiy, A.C. Miller, H. Jain and O. Shpotyuk, Structure of Se-rich As-Se glasses by high-resolution X-ray photoelectron spectroscopy // Phys. Rev. B, 76, p. 125208-1125208-7 (2007).

16. J.F. Moulder, W.F. Stickle, P.E. Sobol, K.D. Bomben, Handbook of X-ray Photoelectron Spectroscopy. Perkin-Elmer Corp., Phys. Electr. Div., Eden Prairie, Minnesota, 1992. 